\title{
Overview of Iodine Propellant Hall Thruster Development Activities at NASA Glenn Research Center
}

\author{
Hani Kamhawi ${ }^{1}$, Thomas Haag ${ }^{2}$, Gabriel Benavides ${ }^{3}$, Tyler Hickman ${ }^{4}$, and Timothy Smith ${ }^{5}$ \\ National Aeronautics and Space Administration Glenn Research Center, Cleveland, Ohio, 44135 \\ George Williams ${ }^{6}$ \\ Ohio Aerospace Institute, Cleveland, Ohio, 44135 \\ James Myers ${ }^{7}$ \\ Vantage Technologies Inc., Cleveland, Ohio, 44135 \\ Kurt Polzin ${ }^{8}$ and John Dankanich ${ }^{9}$ \\ National Aeronautics and Space Administration Marshall Space Flight Center, Huntsville, Alabama, 35812 \\ Larry Byrne ${ }^{10}$, James Szabo ${ }^{11}$, and Lauren Lee ${ }^{12}$ \\ Busek Company Inc., Natick, Massachusetts, 01760
}

\begin{abstract}
NASA is continuing to invest in advancing Hall thruster technologies for implementation in commercial and government missions. There have been several recent iodine Hall propulsion system development activities performed by the team of the NASA Glenn Research Center, the NASA Marshall Space Flight Center, and Busek Co. Inc. In particular, the work focused on qualification of the $200 \mathrm{~W}$ Busek BHT-200-I and the continued development of the $600 \mathrm{~W}$ BHT-600-I Hall thruster propulsion systems. This paper presents an overview of these development activities and also reports on the results of short duration tests that were performed on the engineering model BHT-200-I and the development model BHT-600-I Hall thrusters.
\end{abstract}

\section{Introduction}

perational Hall thrusters currently demonstrate excellent mission performance for power levels between 1 and $10 \mathrm{~kW}$ using xenon propellant. However, the volume and high pressure requirements for xenon propellant storage do not integrate well with small spacecraft. Low-power Hall thruster tests at Busek Co. Inc. found that Hall thruster performance with iodine is very similar to its performance with xenon; ${ }^{1,2}$ however, iodine stores three times as dense as xenon and at subatmospheric pressures. The increase in storage density and reduction in tank pressure can lead to improved spacecraft volume utilization, which can translate to a significant $\Delta \mathrm{V}$ increase relative to xenon propellant for a given electric propulsion system volume.

\footnotetext{
${ }^{1}$ Senior Research Engineer, Electric Propulsion Systems Branch, AIAA Associate Fellow.

${ }^{2}$ Senior Research Engineer, Electric Propulsion Systems Branch, AIAA Senior Member.

${ }^{3}$ Research Engineer, Electric Propulsion Systems Branch, AIAA Senior Member.

${ }^{4}$ Senior Research Engineer, Electric Propulsion Systems Branch, AIAA Senior Member.

${ }^{5}$ Project Manager, Electric Propulsion Systems Branch, AIAA Senior Member.

${ }^{6}$ Senior Research Engineer, Ohio Aerospace Institute, AIAA Associate Fellow.

${ }^{7}$ Senior Research Engineer, Vantage Partners, AIAA Associate Fellow.

${ }^{8}$ Propulsion Research Engineer, Propulsion Systems Department, ER24, AIAA Associate Fellow.

${ }^{9}$ Project Manager, Technology Development and Transfer, ZP30, AIAA Associate Fellow

${ }^{10}$ Senior Project Engineer, Busek Company Inc., AIAA Senior Member.

${ }^{11}$ Chief Scientist of Hall Thrusters, Busek Company Inc., AIAA Associate Fellow.

${ }^{12}$ Engineer, Busek Company Inc., AIAA member.
} 
The use of iodine as an alternative to xenon has been studied for more than a decade. ${ }^{1-4}$ Over that time there have been a wide range of studies focusing on MicroSats (10 to $100 \mathrm{~kg}$ ), suggesting they have the potential to perform significant orbit transfers including geostationary transfer orbit (GTO) to geostationary equatorial orbit (GEO) or deploy a constellation of small spacecraft from a single launch. Studies have also examined an Evolved Expendable Launch Vehicle (EELV), Secondary Payload Adaptor (ESPA), or ESPA Grande class spacecraft, which can perform more than $10 \mathrm{~km} / \mathrm{s}$ of $\Delta \mathrm{V}$ and perform orbit transfers from GTO to the Moon, Mars, Venus, and asteroids. ${ }^{5}$

The Collaborative Modeling for Parametric Assessment of Space Systems (COMPASS) team at NASA Glenn Research Center (GRC) completed a conceptual design of a low-cost iodine Hall thruster demonstration mission in 2012. ${ }^{6}$ The concept was a 6U spacecraft with a modified BHT-200 thruster and a repackaged compact PPU. Even though the initial concept was highly power constrained, included aggressive assumptions, and required significant engineering development work, it showed the viability of a low cost and high value approach to flight demonstrate the iodine Hall thruster technology. Multiple iterations of the concept followed, leading to the Iodine Satellite (iSAT) demonstration mission.

While iodine propellant has advantages for low-power volume constrained systems, ${ }^{1-6}$ there are still challenges to be addressed with propulsion system development. Condensable propellants raise concerns with deposition on the spacecraft and operational complications. Iodine can be corrosive to materials both in the feed system and possibly on the spacecraft during flight. The feed system also has unique challenges, requiring very low-pressure flow control and electrical power to keep the propellant and propellant lines heated. Material compatibility considerations also apply to both the thruster and cathode when making decisions on the coatings and constituent materials.

\section{Background}

NASA's Space Technology Mission Directorate (STMD), under the Small Spacecraft Technology Program (SSTP), approved the iSAT flight project for a rapid demonstration of iodine Hall thruster technology in a 12U configuration. ${ }^{7,8}$ The mission is a partnership between NASA Marshall Space Flight Center (MSFC), NASA GRC, and Busek Co. Inc., with the U.S. Air Force supporting the propulsion technology maturation. The iSat mission will utilize a $200 \mathrm{~W}$ iodine Hall thruster propulsion system to demonstrate small spacecraft maneuverability and mitigate concerns regarding iodine deposition regardless of spacecraft size. Figure 1 presents the current layout of the iSAT spacecraft. The top-level objectives of the project are focused on validating the use of iodine for future missions while demonstrating $\Delta \mathrm{V}$ capability on a secondary small spacecraft. The mission will validate in-space performance of the iodine Hall system and demonstrate relatively high power and high power density in a CubeSat form factor.

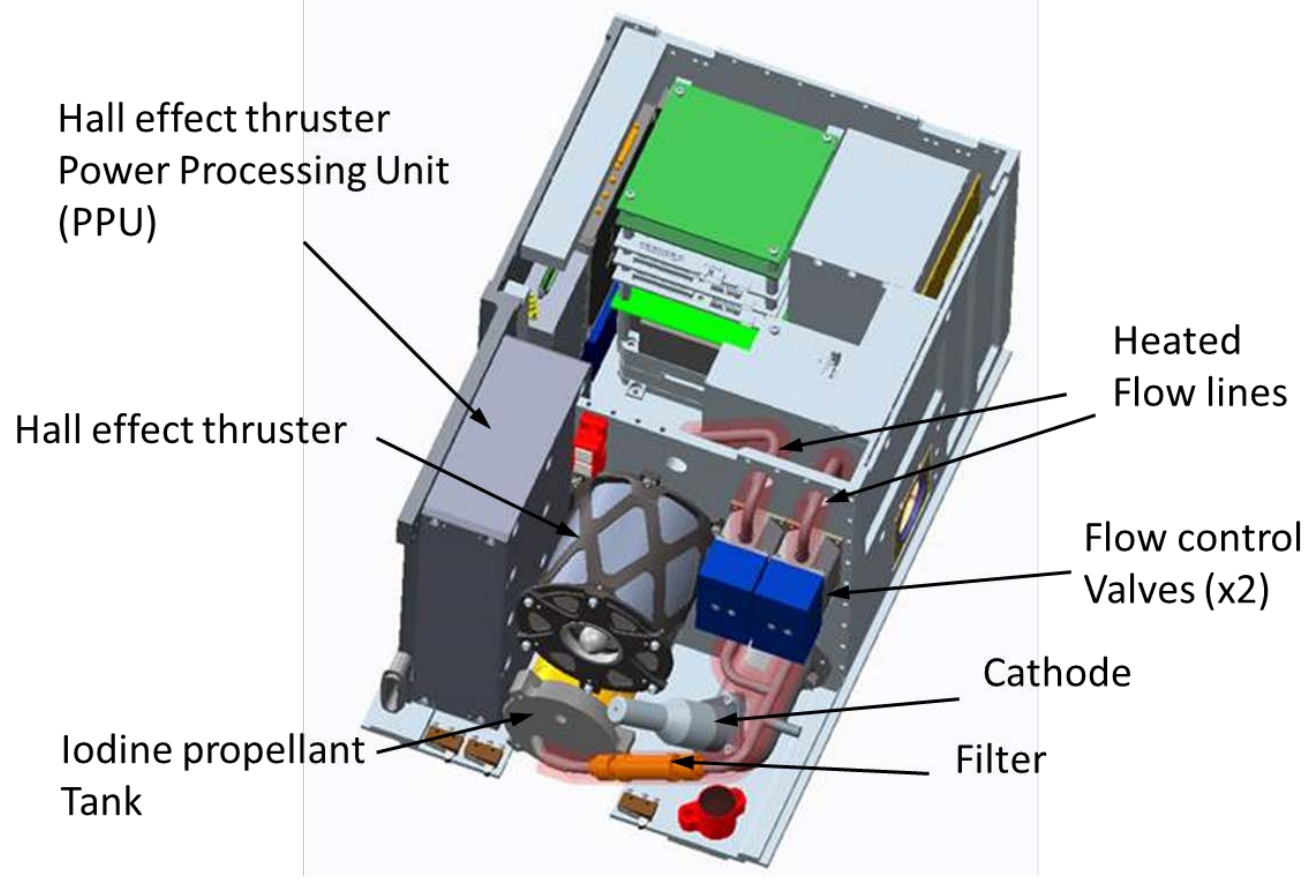

Figure 1. iSAt spacecraft layout showing the propulsion and iodine feed system components. 
Development, test, and analysis focus on five key areas: the Hall thruster, cathode, feed system, power processing unit (PPU), and verification activities. The thruster activities have focused on design and fabrication of the iodine compatible Hall thruster variants (at Busek), while work at NASA GRC has focused on iodine compatible Hall thruster testing and thermal modeling. The cathode activities (at Busek) have focused on cerium hexaboride $\left(\mathrm{CeB}_{6}\right)$, lanthanum hexaboride $\left(\mathrm{LaB}_{6}\right)$, and electride electron emitters. Feed system development conducted by NASA MSFC has focused on sublimation control, high-voltage isolation, avoidance of propellant condensation, and iodine compatibility. ${ }^{9,10}$ The PPU development activities at Busek are focused on the development of a flight $200 \mathrm{~W}$ compact PPU for demonstration on iSAT and the development of an engineering model $600 \mathrm{~W}$ PPU. NASA GRC is supporting the Busek PPU activities by developing thermal models of the PPUs. The propulsion system verification activities have been led by NASA GRC (iSat Propulsion Lead) in collaboration with NASA MSFC and Busek to verify the iSat propulsion system functionality, robustness, and performance.

This paper provides an overview of the NASA GRC activities conducted in support of advancing the technology readiness level of iodine Hall propulsion systems. In Section III, a summary of the thermal modeling activities at NASA GRC is presented; Section IV presents the experimental apparatus used in the Hall thruster tests at NASA GRC; Section V presents the results from the 80 hour test of the EM BHT-200-I thruster; Section VI presents the results from the duration tests of the BHT-600-I thruster; and Section VII presents a summary and plans for future iodine development activities at NASA GRC.

\section{Thermal Modeling}

NASA GRC is developing detailed thermal models of the BHT-200-I Hall system and the BHT-600-I thruster. In support of the iSAT project, NASA GRC is performing detailed thermal modeling of the propulsion subsystem. That includes thermal modeling of the BHT-200-I thruster, the BHT-200-I cathode assembly, the BHT-200-I compact PPU, iodine tank, PFCV, propellant lines and heaters, and the iSAT propulsion panel. Figure 2 shows the iSAT propulsion panel thermal model.

Results from the BHT-200-I magnet-only tests performed at Busek, and the 80 hour duration test discussed in Section VI were used to validate the thruster thermal model. Thermal modeling of the cathode unit was also performed to evaluate whether separate line heaters have to be added inside the cathode mount pedestal to assure that no iodine condensation occurs in the cathode feedline. Detailed thermal modeling of the iSAT PPU is currently being performed to confirm the integrity of the PPU thermal design and to confirm that the iSAT spacecraft and space environment will not cause the PPU operating temperatures to exceed the PPU specifications.

Finally, a detailed thermal model of the BHT-600-I has also been developed. The model results will be compared to temperature data collected during testing of the BHT-600-I and will be used to inform the BHT-600-I design. Figure 3 shows a result from the BHT-600-I thermal model.
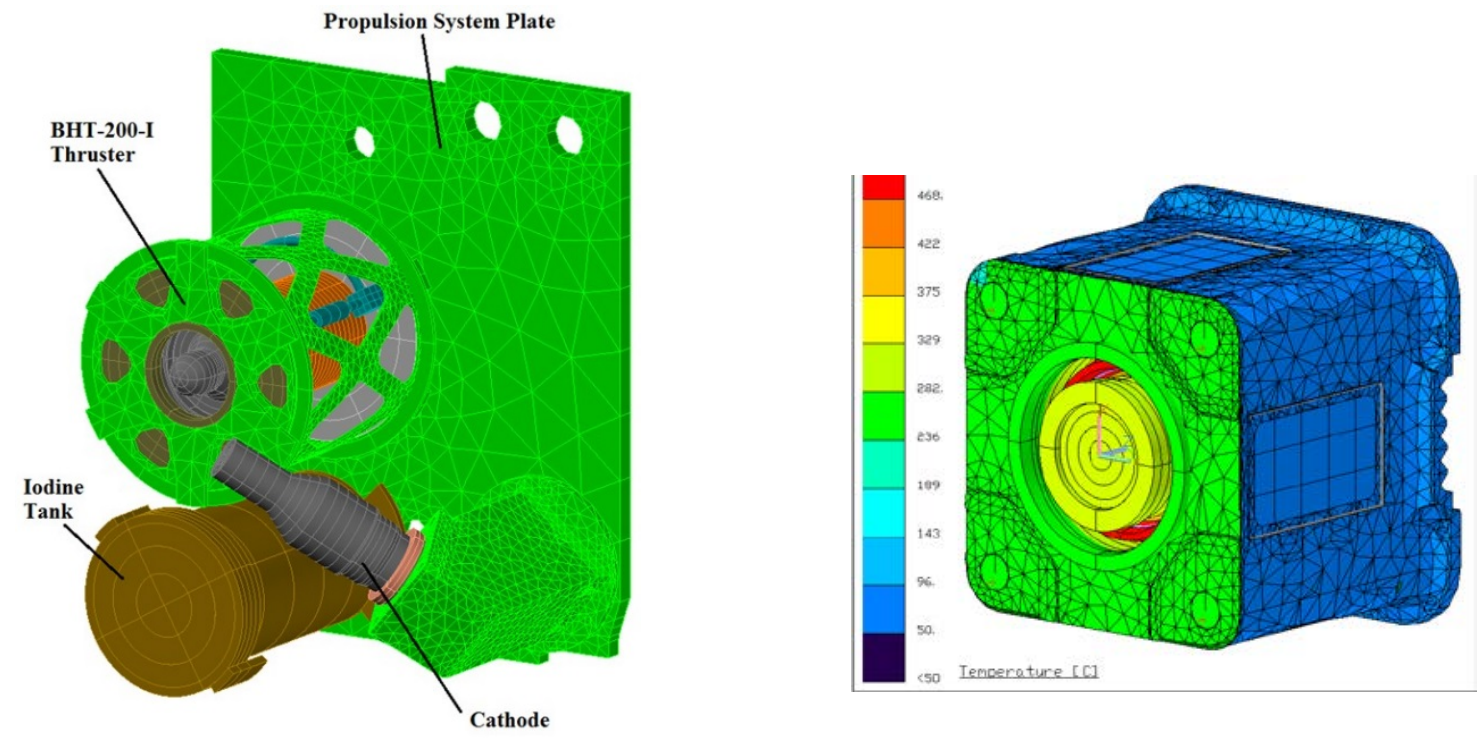

Figure 2. Thermal model of the iSAT propulsion panel includes thruster, cathode, feed system, and PPU.

Figure 3. Thermal model of the BHT-600-I. 


\section{Experimental Apparatus}

\section{A. BHT-200-I}

The iSAT thruster is a derivative of the BHT-200 flight thruster. The BHT-200 was the first American Hall effect thruster flown in space and was launched in 2006 as a part of the TacSat- 2 project. ${ }^{11}$ The thruster has been studied extensively and provides a good benchmark for comparing performance variances from the iodine version of the thruster - the BHT-200-I, shown in Fig. 4. The iodine thruster is distinguished from the nominal BHT-200 by the materials of construction, geometry of the anode, and iodine-resistant coatings. The anode and gas flow lines are made from a nonmagnetic, iodine-resistant alloy. The propellant voltage isolator is made from iodine-resistant metals and brazes. The gas distributor was also completely redesigned to allow use of multiple materials.

\section{B. BHT-600-I}

The BHT-600-I shown in Fig. 5 is designed to operate at a nominal discharge power of $600 \mathrm{~W}$ with iodine. The $600 \mathrm{~W}$ thruster is sized for satellite station keeping and orbit maneuvering, either by itself or within a cluster; it is not being developed for iSAT. The discharge channel exit rings are made of boron nitride. The hollow cathode is located distal to the discharge. A highvoltage ceramic break electrically isolates the anode from the propellant line. More details about the thruster can be found in Ref. 12.

\section{Hollow Cathode}

The hollow cathode assemblies used in the NASA GRC tests include cathode assemblies developed by Busek and NASA GRC. A Busek porous tungsten $\mathrm{BaO}$ emitter-based cathode was used with the BHT-200-I thruster tests operating on xenon propellant. For the BHT-600-I tests, two assemblies were used. During the first duration test, a Busek-manufactured cerium hexaboride $\left(\mathrm{CeB}_{6}\right)$ cathode was used, and for the second duration tests, a NASA GRC porous tungsten $\mathrm{BaO}$ impregnated emitter was used; both cathode assemblies were operated on xenon propellant.

\section{Inverted Pendulum Thrust Stand}

A null-type water-cooled inverted pendulum thrust stand was implemented during thruster performance evaluation. ${ }^{13}$ The power cables were fed from the vacuum feedthrough to the thruster using a "water fall" configuration to minimize thermal drift of the thrust stand readings. In situ thrust stand calibrations were performed prior, during, and after thruster testing. Corrections were incorporated into the reported thrust data. Thrust measurement uncertainty was estimated at $2 \%$ of measured value.

\section{E. Power Supply, Data Acquisition, and Control Systems}

For this test campaign, the BHT-200-I and BHT-600-I thrusters were powered with a laboratory power rack that contained the power supplies for the discharge, inner and outer electromagnets, cathode heater, cathode keeper, propellant line heaters, and an iodine feed system control board designed and manufactured by MSFC.

The data acquisition system used was a multiplexed datalogger with computer interface. The datalogger monitored the voltages, currents, temperatures, chamber pressure, and thrust every 2 seconds during performance testing. The computer interface had the additional benefit of allowing a number of monitored channels to be monitored with failsafe limits for unattended operation. The uncertainties of the datalogger measurements were $0.5 \%$ for the voltage and current measurements.

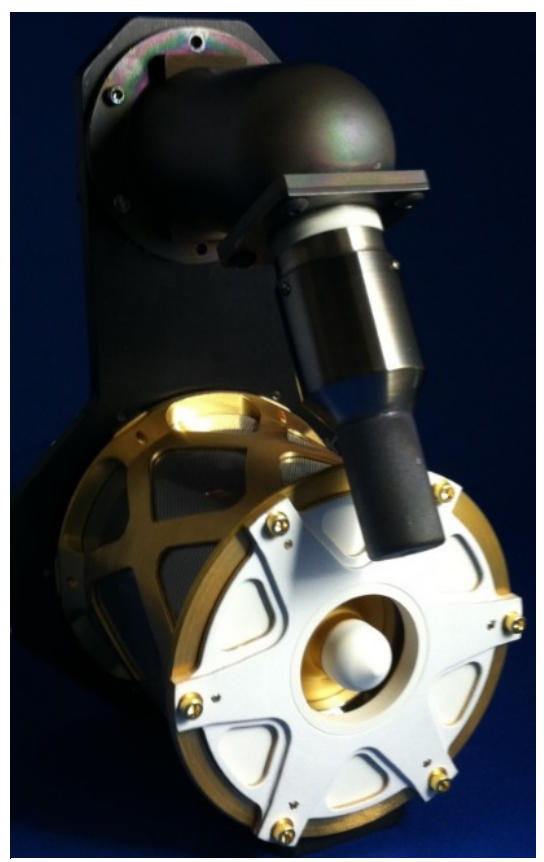

Figure 4. Photograph of the BHT-200-I thruster.

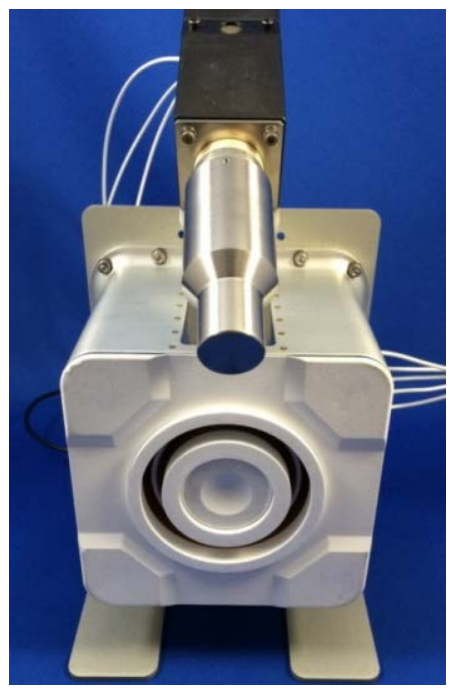

Figure 5. Photograph of the BHT-600-I. 


\section{F. Vacuum Facility}

Propulsion system testing is being performed in GRC's Vacuum Facility 7 (VF-7), shown in Fig. 6 (left). VF-7 is an oil diffusion pump-evacuated facility that is $10 \mathrm{ft}(3 \mathrm{~m})$ in diameter and $15 \mathrm{ft}(4.6 \mathrm{~m})$ long. The facility has been modified for compatibility with iodine propellant and has a typical base pressure of $2 \times 10^{-7}$ Torr. Currently, liquid nitrogen cooled chevrons are used to collect the expelled iodine propellant during thruster firing. After test completion, specially installed heating lamps are used to elevate the chevron temperatures to facilitate iodine propellant venting, and a specially installed pumping train is used to exhaust the iodine propellant. In the near future, a newly constructed cryotarget, shown in Fig.6 (right), will be installed to serve as a beam dump for the iodine plume, its main function is to collect the iodine.
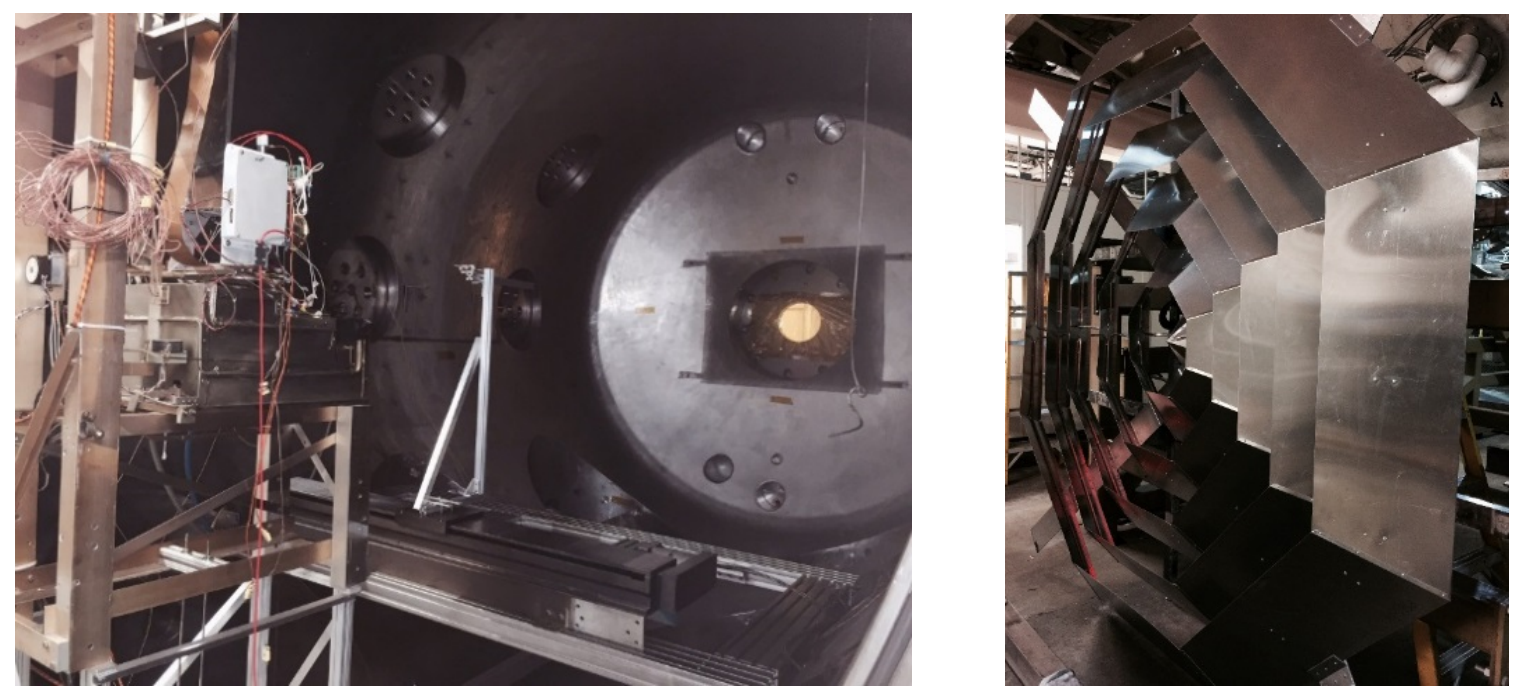

Figure 6. (Left) VF-7 $10 \mathrm{ft}(3 \mathrm{~m})$ diameter facility will be used for long duration thruster tests and plasma diagnostics development and tests. (Right) Cryogenically-cooled iodine collection chevrons.

\section{G. Flow System}

A laboratory iodine propellant feed system designed, fabricated, and manufactured at NASA GRC was used to supply iodine propellant to the thruster. The feed system incorporates a VACCO Industries-designed and manufactured iodine compatible proportional flow control valve (PFCV). Figure 7 presents the layout of the iodine

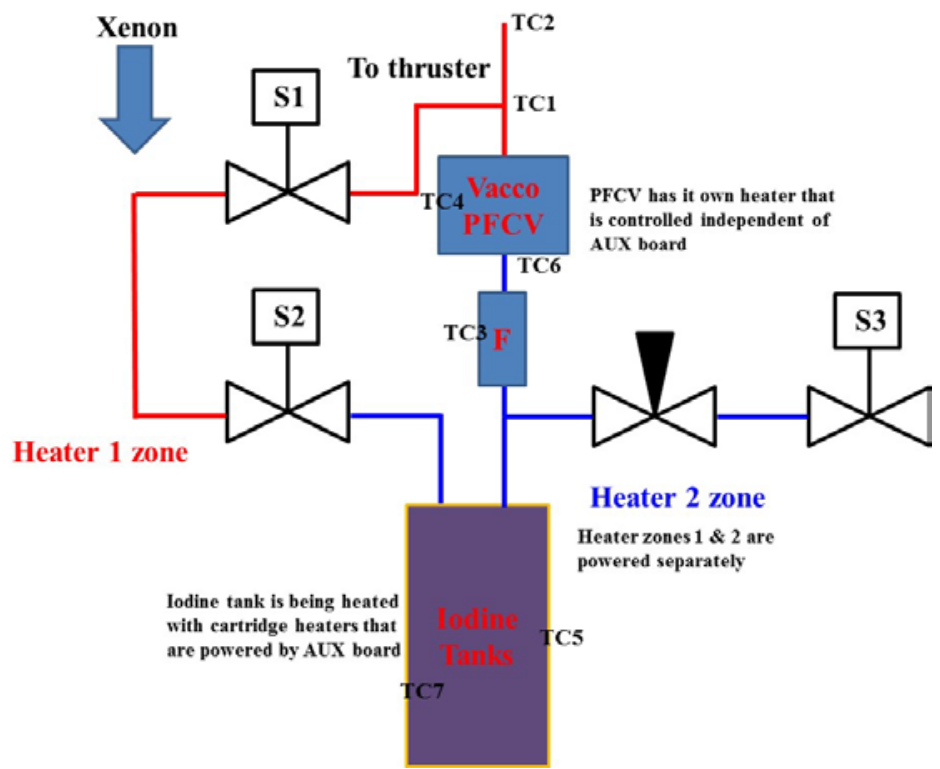

Figure 7. Iodine propellant feed system schematic showing the various components and thermocouple locations. 
feed system employed in this test campaign. The feed system setup allows the option of operating the thruster with xenon or iodine propellants. Xenon propellant operation is performed by opening solenoid valve S1 and closing solenoid valves S2 and S3 and also closing the PFCV. For iodine thruster operation, all solenoid valves are closed (S1, S2, and S3) and the PFCV is opened. The feed system was instrumented with several thermocouples to monitor the temperature of the propellant feedlines, filter, tank, and PFCV. The propellant lines and the PFCV were wrapped with commercial heat tape. A MSFC-designed control board was used to control the PFCV and to power the iodine tank commercial cartridge heaters.

A laboratory propellant feed system was used to supply xenon to the BHT-200-I and BHT-600-I thrusters. The propellant feed system utilized two mass flow controllers (MFC); a 100 and 10 sccm MFCs supplied xenon propellant to the thruster and cathode, respectively. The MFC calibration curves indicated that the anode and cathode flow rates uncertainty is $\leq 2 \%$ of set value.

\section{H. Time Resolved Thruster Telemetry}

The temporal behavior of the BHT-200-I and the BHT-600-I Hall thrusters discharge current waveforms was continuously monitored with an oscilloscope. The Tektronix oscilloscope internally functionally calculated the root mean square (RMS), peak-to-peak ( $\mathrm{Pk} 2 \mathrm{Pk}$ ), and mean value where appropriate. The discharge current waveforms were analyzed to generate the power spectral density (PSD) plots of the selected operating conditions.

\section{BHT-200-I 80 Hours Duration Test}

The BHT-200-I EM thruster has undergone an 80 hours duration test in VF-7. The 80 hours is the projected maximum duration of the ISAT mission. ${ }^{9}$ The duration test objectives were:

- Validate the design modifications of the EM thruster prior to building the qualification and flight model thrusters;

- Measure the thrust produced by thruster when fueled with xenon and iodine;

- Measure temperatures of selected thruster components to confirm design thermal viability and to provide critical data for thermal model validation; and

- Demonstrate robust and reliable PFCV operation.

For this test, the iodine feed system was instrumented with seven thermocouples that included thermocouples on the PFCV, iodine tank, filter, and propellant lines. The thruster was instrumented with six thermocouples that were placed on the inner electromagnet, propellant isolator, outer front pole, back pole, and thruster housing. In addition, optical probes were used to record the emission spectra of the thruster plume. Baseline performance was collected with the thruster operating on xenon propellant. The measured thruster performance with xenon matched levels reported earlier by Busek.

Next the thruster was operated with iodine propellant. The iodine tank temperature was set to approximately 90 ${ }^{\circ} \mathrm{C}$. The PFCV and propellant line temperatures were set to approximately $113^{\circ} \mathrm{C}$. After the prescribed iodine tank and propellant line temperatures were achieved, iodine propellant was introduced to the thruster by opening the PFCV. The PFCV applied voltage was varied to adjust the iodine flow rate until the desired discharge current was achieved. Figure 8 shows the thruster operating on iodine with the cathode operating on xenon. Figure 9 shows the BHT-200-I thruster as installed on the inverted pendulum thrust stand in GRC VF-7.

The 80 hours of thruster operation was attained over 6 days of testing. Figure 10 presents the discharge voltage and current (on secondary axis) profiles during the test. The thruster was operated at a discharge voltage of $250 \mathrm{~V}$ with a target discharge current of 0.8 A resulting in a thruster discharge power of $200 \mathrm{~W}$. The xenon fueled cathode was operated with a keeper current of 0.5 A. No closed-loop control on the PFCV was set up for this test; as such, the thruster shutdowns occurred when the thruster discharge current drifted outside a range set by the test operator. During day 2 of the duration test it was observed that the PFCV failed to close completely, and iodine would flow through the PFCV even when it was commanded closed. The loss of the ability to close the PFCV necessitated use of the iodine tank temperature (iodine tank heaters) as an alternate means of controlling the iodine flow.

Figure 11 presents the iodine feed system component temperatures and discharge current (on secondary axis) profiles during the 80 hour test. As is shown in Fig 11, the internal iodine tank temperature was set to between 85 and $90{ }^{\circ} \mathrm{C}$; the propellant line component temperatures including the filter and the PFCV were operated at temperatures above $113^{\circ} \mathrm{C}$. During days 5 and 6 , the iodine tank temperature was increased to maintain the iodine flow necessary to generate a discharge current of approximately $0.8 \mathrm{~A}$. 


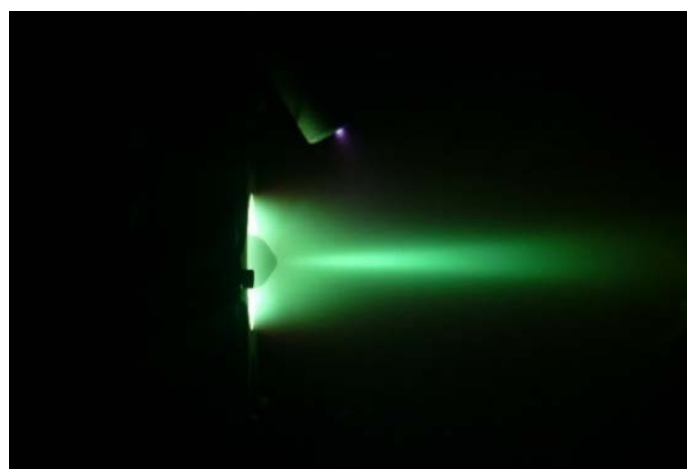

Figure 8. Photograph of the BHT-200 thruster operating with iodine and cathode operating on xenon.

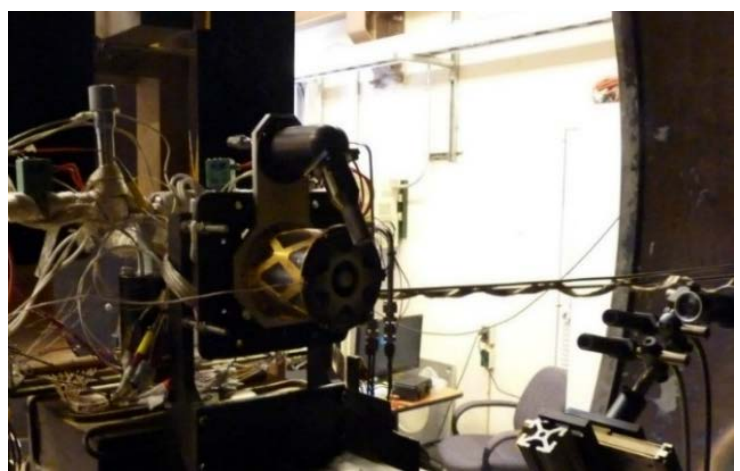

Figure 9. BHT-200 thruster and iodine feed system installed on the inverted pendulum thruster stand in VF-7. Optical probes are to the right of picture.

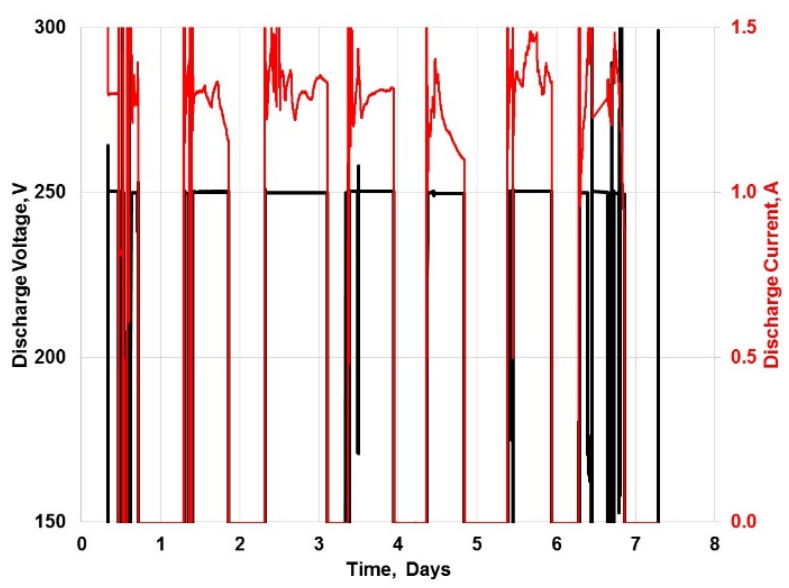

Figure 10. Discharge voltage and current magnitudes during the $\mathbf{8 0}$ hours test. Note that the reported discharge current magnitudes include a 0.5A keeper current.

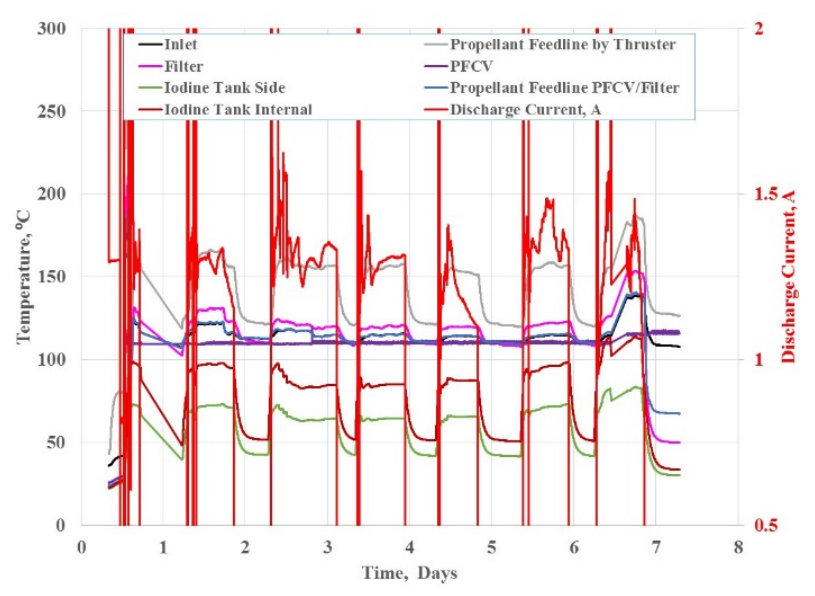

Figure 11. Iodine feed system component temperatures during the $\mathbf{8 0}$ hours duration test

Figure 12 presents the thrust and discharge current (on secondary axis) profiles during the 80 hours test. The thrust levels in Figure 12 indicate thrust levels similar to what was measured during initial thruster tests prior to start of the 80 hours duration test. Figure 13 presents the thruster component temperatures and discharge current (on secondary axis) profiles during the 80 hours test. These measured values were within the prescribed maximum temperature limits set by Busek. Measurements indicated that a peak coil temperature of $\sim 255^{\circ} \mathrm{C}$ was reached during thruster operation. Additionally, the upstream propellant isolator temperature of $\sim 210^{\circ} \mathrm{C}$ was maintained during the thruster hot fire tests; this is significant because at these temperatures no iodine condensation can occur.

Figure 14 presents a comparison of the PSDs for operation with xenon and iodine propellants at magnet current settings of 1.1 and 1.3 A. PSDs presented in Fig. 14 show that xenon operation had a high peak at $1 \mathrm{kHz}$ (speculation is that it might be noise pickup on the current waveform signal), but otherwise the two propellants had similar PSD profiles with the breathing mode frequency occurring between 30 and $40 \mathrm{kHz}$. 


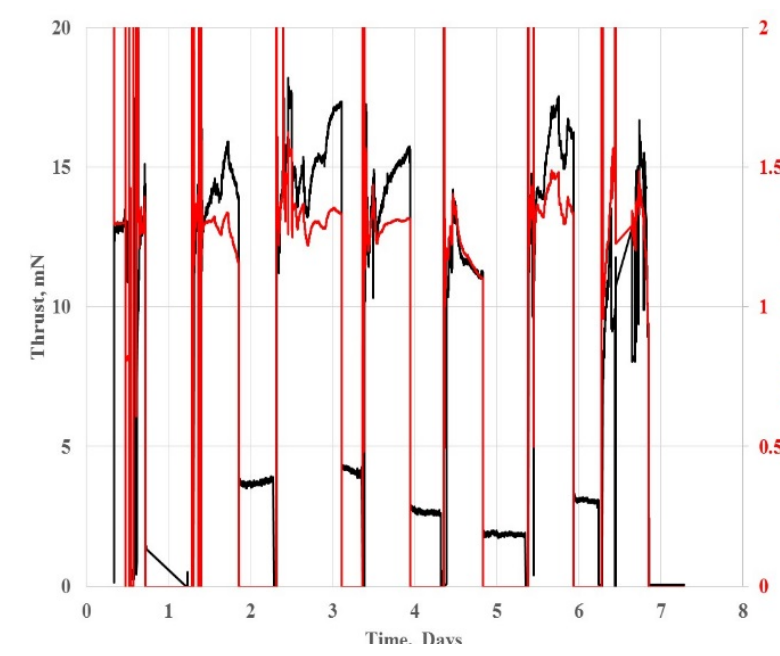

Figure 12. Discharge current and thrust magnitudes during the 80 hours test.

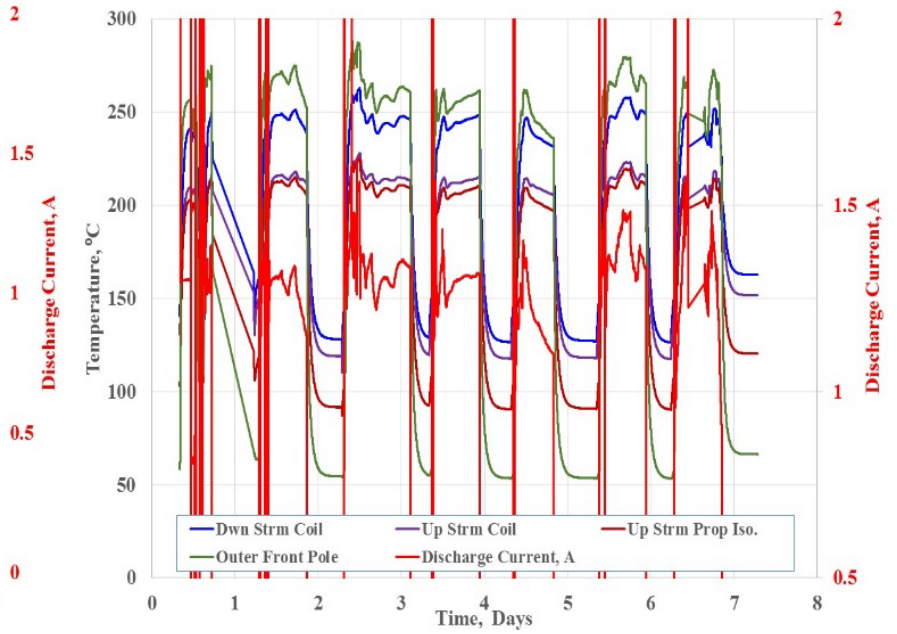

Figure 13. Thruster component temperatures during the 80 hours test.

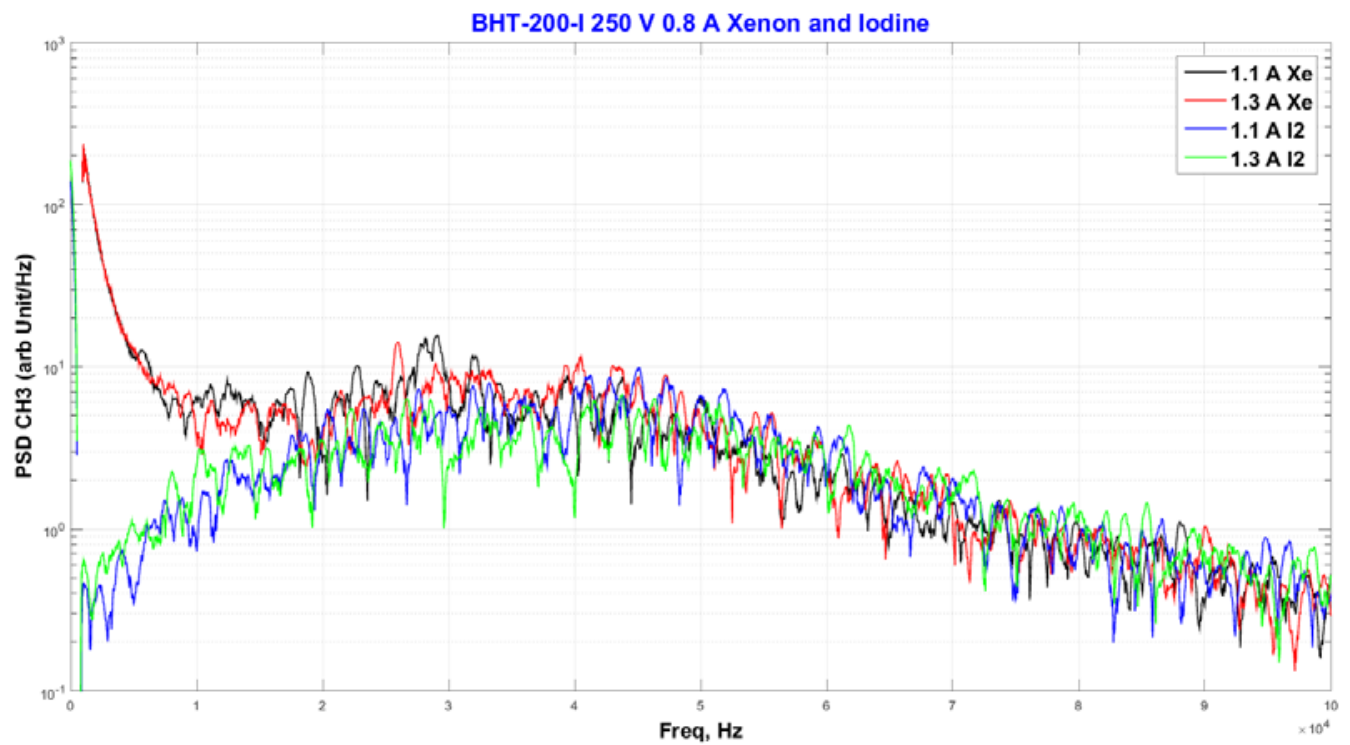

Figure 14. Power Spectral Density analysis of the BHT-200-I discharge current waveforms for xenon and iodine propellant operation.

Table 1 lists the measured thrust levels with xenon and iodine propellant at the beginning and end of the 80 hour test. Results in Table 1 indicate an almost identical thruster performance. For the 80 hour test, approximately $300 \mathrm{~g}$ of iodine was processed as determined by measuring the iodine tank mass before and after the test. However, due to the PFCV failure not all the iodine propellant was exhausted during thruster operation.

Table 1 BHT-200-I thrust levels at the beginning and end of the 80 hours duration test.

\begin{tabular}{|c|c|c|c|c|}
\hline & \multicolumn{2}{|c|}{ Ohour } & \multicolumn{2}{c|}{80 hour } \\
\hline & Xenon & Iodine & Xenon & Iodine \\
\hline Discharge Voltage, V & 250 & 250 & 250 & 250 \\
\hline Discharge Current, A & 0.81 & 0.83 & 0.80 & 0.84 \\
\hline Thrust, mN & 12.9 & 14.2 & 13.2 & 13.9 \\
\hline
\end{tabular}

8

American Institute of Aeronautics and Astronautics 
Nonintrusive characterization of the near-field plasma of Hall thrusters via optical emission spectroscopy (OES) has been employed during the BHT-200-I thruster tests. Optical emission spectroscopy has been used successfully to identify changes in plasma structure, changes in the amount of eroded material with thruster operating condition, and estimation of various plasma parameters such as electron temperature and electron number density. ${ }^{14-25}$. In this investigation, OES was conducted to compare the plasma structures associated with xenon and iodine operation, determine if the plasma structure changes significantly over extended operation, and to monitor boron emission as an indicator of erosion of BN surfaces.

The optical probes used in this study were constructed using $1.25 \mathrm{~cm}$ diameter UV-silica lenses and flat windows, optical tubes, and SMA fiber optic connections. Lenses which matched the acceptance angle of the $400 \mu \mathrm{m}$ diameter fiber optic cables and protective windows were incorporated in all of the probes. One probe collected light from a collimated column $3 \mathrm{~mm}$ in diameter across the center of the thruster. A second probe collected light from a similar $3 \mathrm{~mm}$ diameter column across the channel at the 12:00 position. Both probes were translated together up to $50 \mathrm{~mm}$ downstream of the exit plane. The translation stage was homed between scans to preclude the buildup of positioning errors.

Single-fiber, $400 \mu \mathrm{m}$ core diameter, metal-jacketed fiber optic cables coupled the probes to vacuum feedthroughs and the feedthroughs to a fiber optic multiplexer located external to the vacuum chamber. Similar fiber optic cables connected the feed-throughs to digital spectrometers capable of measuring between $220 \mathrm{~nm}$ and $910 \mathrm{~nm}$. The transmission through the probes was calibrated before, during, and after each test. Standard Xe and W lamps were placed at the same distance as the location of measurement in the thruster for each probe, and spectral data were recorded using the entirety of the probe-fiber-feedthrough system before and after each series of testing. Minor variations were noted which were likely the result of sputter deposition on the protective windows. The deposition tended to preferentially reduce the signal strength below a wavelength of $350 \mathrm{~nm}$. However, the degradation was negligible. Calibrations were performed during a test sequence by recording spectra at repeated thruster operating conditions. No significant changes in line intensities were noted, and the slight degradation of the UV signal was recorded and used in the normalization of the data.

Figure 15 shows the trend in singly ionized iodine (I II) emission strengths for both OES probes as a function of distance downstream of the thruster exit plane for $563 \mathrm{~nm}$. Figure 16 shows the same trends for I II emission at 533 $\mathrm{nm}$. The $533 \mathrm{~nm}$ upper-state differs by roughly $1 \mathrm{eV}$ from that of the $563 \mathrm{~nm}$ transition, bracketing the range of upper states populated for visible emission and therefore capturing different excitation rates. The very similar emission frequencies (differing in energy by only $0.12 \mathrm{eV}$ ) should remove effects of collisional de-excitation and degradation of the optical path. Each trace in the plots is normalized to its own maximum for the given scan. It is stipulated that trends in both figures show that the ion density downstream of the discharge channel decreases rapidly, but there is an increase in the density along the centerline of the thruster. The density appears to maximize between 1.5 and $2.5 \mathrm{~cm}$ downstream of the exit plane. Figures 15 and 16 also show that there was no significant change in the plasma structure

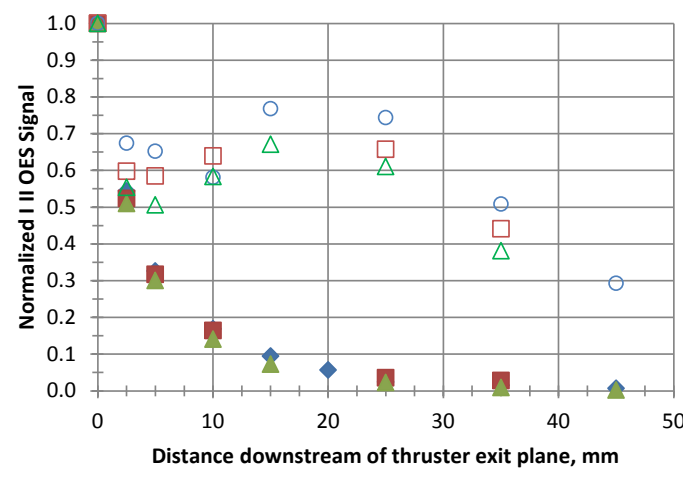

- channel center, start, I II, 563 I

Channel center, mid, I II, $563 \mathrm{n}$

$\triangle$ channel center, end, I II, $563 \mathrm{n}$

Othruster center, start, I II 563 r

$\square$ thruster center,mid, I II $563 \mathrm{nn}$

$\triangle$ thruster center, end, I II, 563 n

Figure 15. Normalized I II $563 \mathrm{~nm}$ OES signals downstream of the thruster for two radial locations. 
over the course of the test. There was a continuous decrease in OES signal strength over the course of the test, but this is more likely due to contamination of the optics by iodine deposition or backsputter coating.

Figure 17 shows the trend in neutral iodine (I I) emission strengths for both OES probes as a function of distance downstream of the thruster exit plane for the $804 \mathrm{~nm}$ transition. The trends suggest the neutral density decreases rapidly downstream of the thruster independent of radial position. Similar trends were seen with other I I transitions, suggesting the trends are not dependent on excitation and de-excitation mechanisms. The trends seen with iodine are also seen when the thruster is operating on xenon. Figure 18 shows the trends in Xe II downstream of the thruster for both OES probes for the $541 \mathrm{~nm}$ transition. Note that the trends are nearly identical to those seen in Fig. 16. Figure 19 shows that the Xe I density also decreases rapidly downstream of the thruster.

Strong boron (B I) emission was detected by both probes for both $\mathrm{Xe}$ and $\mathrm{I}_{2}$ operation. Figure 20 shows a typical OES spectra near the $249.8 \mathrm{~nm}$ B I transition during operation on iodine. Note the near lack of other lines within $5 \mathrm{~nm}$ which is not the case during operation on xenon. Iodine ion (I II) lines are also noted in the figure. For a $250 \mathrm{~V}$ discharge voltage and 0.8

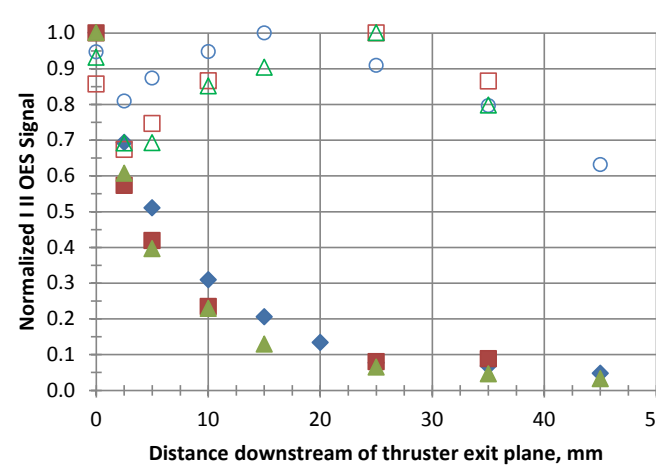

$\checkmark$ channel center, start, I II, 534 nm 口channel center, mid, I II, 534 nm $\triangle$ channel center, end, I II, 534 nm Othruster center, start, I || 533 nm $\square$ thruster center,mid, I II 533 nm $\triangle$ thruster center, end, I II, $533 \mathrm{~nm}$

Figure 16. Normalized I II 533 nm OES signals downstream of the thruster for two radial locations.

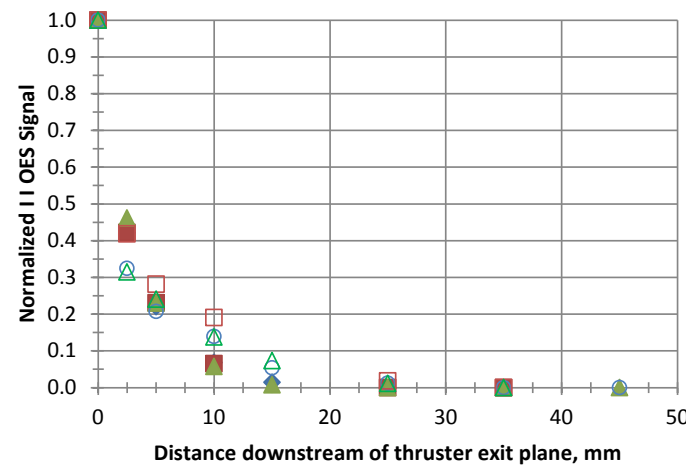

channel center, start, II, 804 r channel center, mid, II, $804 \mathrm{nl}$ $\Delta$ channel center, end, II, $804 \mathrm{nl}$ Othruster center, start, II, 804 । $\square$ thruster center,mid, II, $804 \mathrm{nr}$ $\triangle$ thruster center, end, $11,804 \mathrm{n}$

Figure 17. Normalized I I 804 nm OES signals downstream of the thruster for two radial locations.

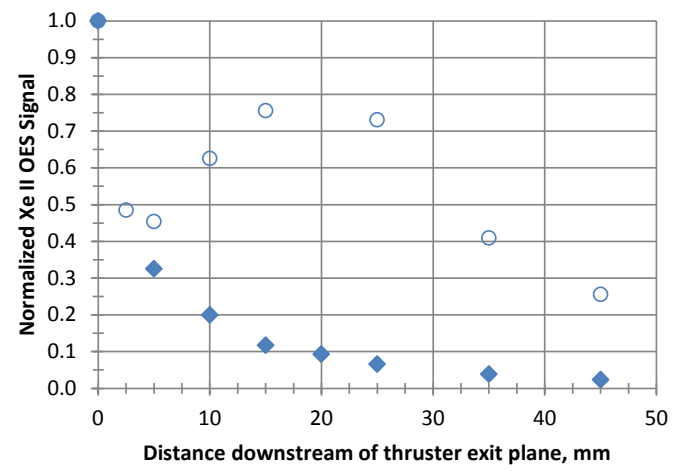

channel center, start, Xe II, 541 । Othruster center, Xe II $541 \mathrm{~nm}$

Figure 18. Normalized Xe II $541 \mathrm{~nm}$ OES signals downstream of the thruster for two radial locations.

A discharge current, at the exit plane the B I OES signal was roughly twice that for operation on iodine as that for operation on xenon. The B I OES signals decreased significantly for operation on both iodine and xenon when the thruster was operated at $200 \mathrm{~V}$. Over the duration of testing, the relative strength of the B I OES signals increased by about $20 \%$ with respect to the I II OES signals which suggests that the erosion of the BN surfaces was increasing. However, the uncertainty associated with these measurements is large, and the data offer only a qualitative assessment.

Trends in neutral iodine are consistent with those presented in Chiu and Prince operating the BHT-200 on both Xe and $\mathrm{I}_{2}$ in 2012. ${ }^{26}$ In that testing, the thruster was operated typically at a discharge voltage of $254 \mathrm{~V}$ and discharge current of 0.78 A. However, neither the Xe I nor the I II trends observed in this testing are consistent with those seen by Chiu and Prince. (Xe II trends are not presented in Chiu and Prince.) Xenon neutral OES trends peak roughly $1 \mathrm{~cm}$ further downstream of the thruster exit plane than the I I trends instead of following the same trends (I I and Xe I). 


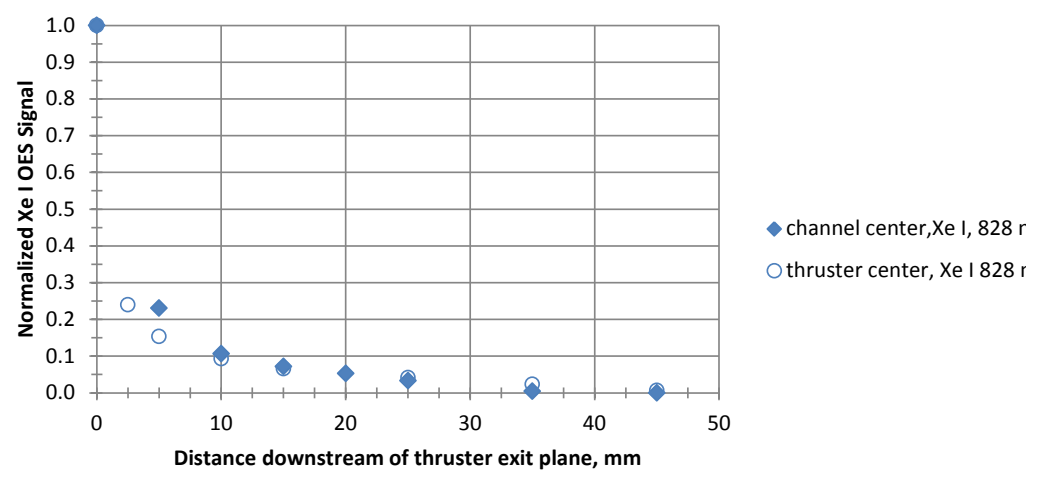

Figure 19. Normalized Xe I $804 \mathrm{~nm}$ OES signals downstream of the thruster for two radial locations.

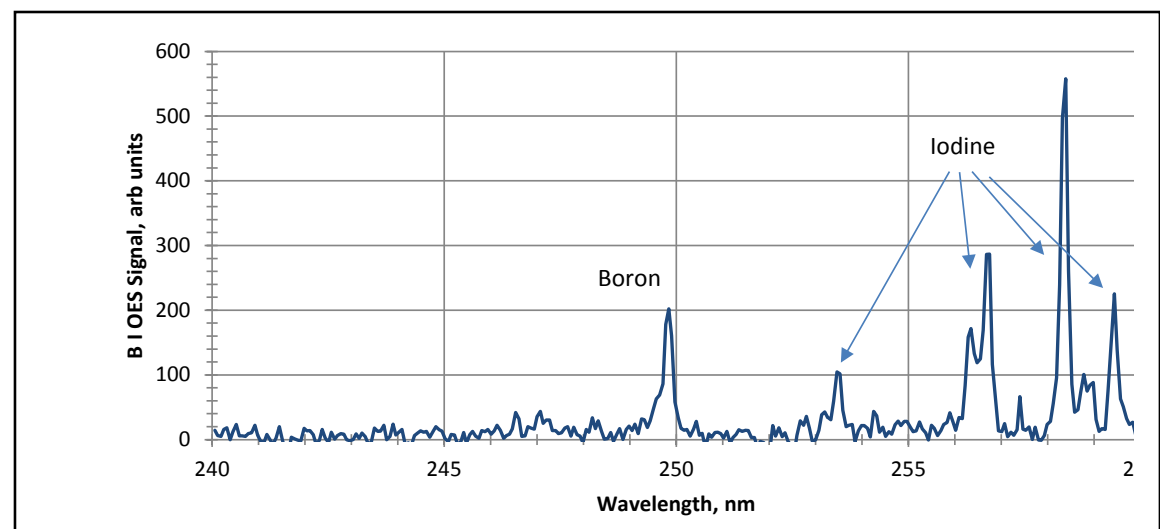

Figure 20. Typical OES signal showing B I and I II emission.

Singly ionized iodine OES signals decrease more rapidly downstream of the channel exit, suggesting that ionization is occurring at or within the exit area of the thruster. Extended I II OES downstream of the thruster with the absence of I I OES suggests a lack of charge exchange collisions with low-energy electron collisions resulting in the plasma glow. All of these differences could result from the differences in background pressure.

\section{BHT-600-I Performance Tests}

The BHT-600-I thruster was also tested at NASA GRC in VF-7. The thruster is a modified version of Busek's BHT-600 and is being developed for high propellant throughput capability. ${ }^{26}$ The main objective of the tests was to evaluate the performance of the thruster with both xenon and iodine propellants and to perform extended duration tests with iodine propellant to uncover any degradation or change in thruster performance or components due to extended exposure to iodine propellant. Two tests were performed with Test 1 lasting 34 hours and Test 2 lasting 46 hours in duration.

Test 1 was an attended test that utilized the same iodine feed system shown in Figure 7. The cathode assembly used in this test was a $\mathrm{CeB}_{6}$ assembly developed by Busek, and the cathode was operated on xenon propellant. Prior to testing with iodine, the thruster performance baseline was established by operating on xenon propellant. Thruster tests with xenon were performed at discharge power levels of 200,300,400,500, and $600 \mathrm{~W}$ at discharge voltages of 200, 250, and $300 \mathrm{~V}$. Table 2 summarizes the measured thruster performance. The thruster operation was then transitioned to iodine propellant and the thruster was continuously operated for approximately 34 hours. Table 3 presents the thruster performance on iodine propellant. Most of the thruster operation was performed at a discharge voltage of $300 \mathrm{~V}$ and a discharge current of $2 \mathrm{~A}$. After exhausting all of the iodine in the tank ( $300 \mathrm{~g})$, the thruster performance was re-evaluated with xenon propellant, and test results indicated no change in the xenon thruster performance. Table 4 presents a summary of the thrust levels with xenon and iodine propellants at the beginning and end of the test. Results presented in Table 4 indicate that the thruster performance did not change after 34 hours of operation with iodine propellant. 
Figure 21 presents the discharge current and discharge voltage variations during the 34 hour test. To regulate the discharge current, thermal throttling of the iodine tank temperature was performed due to the failure of the PFCV. Although thermal throttling of the tank temperature is not ideal for regulating the iodine flow to the thruster, it provided a means for "slow" current regulation. Figure 22 presents the thruster discharge current and thrust variations during the 34 hour duration test. Although the thrust was corrected for thermal drift, not having taken periodic and frequent zero thrust measurements increased the uncertainty of the thrust measurement during iodine propellant operation. Figure 23 presents the iodine feed system component temperatures and the discharge current (on secondary axis) profiles during the 34 hour duration test. Similar to the BHT-200-I duration test, the feed system components were maintained at temperatures above $113^{\circ} \mathrm{C}$ to prevent iodine condensation within the feed system components.

Figure 24 presents the discharge current waveforms PSDs for xenon and iodine propellant operation at 200, 250, and $300 \mathrm{~V}$ operation. Unlike the BHT-200-I, there is a noticeable difference between the xenon and iodine propellant PSDs. For xenon, at a discharge voltage of 200 and $250 \mathrm{~V}$, the dominant breathing mode frequency is at $\sim 10 \mathrm{kHz}$, and it shifts to $35 \mathrm{kHz}$ when the thruster is operated at a discharge voltage of $300 \mathrm{~V}$. For iodine operation at discharge voltages of 200 and $250 \mathrm{~V}$, the magnitude of the PSD peaks is two orders of magnitude lower than those for xenon, but the peaks occur at approximately $10 \mathrm{kHz}$ which is similar to xenon. At a discharge voltage of $300 \mathrm{~V}$, the thruster dominant frequency shifts to $\sim 35 \mathrm{kHz}$ but with a peak magnitude that is significantly lower than xenon. The lower peaks attained during iodine operation indicate that lower discharge Pk2Pk and RMS magnitudes occur during iodine operation when compared to xenon.

Table 2. BHT-600-I xenon propellant measured thruster performance at NASA GRC VF-7.

\begin{tabular}{|c|c|c|c|c|}
\hline $\begin{array}{c}\text { Discharge } \\
\text { Voltage, V }\end{array}$ & $\begin{array}{c}\text { Discharge } \\
\text { Current, A }\end{array}$ & $\begin{array}{c}\text { Discharge } \\
\text { Power, W }\end{array}$ & $\begin{array}{c}\text { Thrust, } \\
\text { mN }\end{array}$ & $\begin{array}{c}\text { Anode } \\
\text { Efficiency }\end{array}$ \\
\hline 200 & 1.00 & 200 & 13.3 & 0.31 \\
\hline 200 & 2.00 & 400 & 25.7 & 0.35 \\
\hline 250 & 0.79 & 198 & 12.6 & 0.35 \\
\hline 250 & 1.20 & 300 & 19.4 & 0.40 \\
\hline 250 & 1.60 & 400 & 26.2 & 0.42 \\
\hline 250 & 2.00 & 500 & 33.7 & 0.46 \\
\hline 250 & 2.40 & 600 & 40.6 & 0.47 \\
\hline 300 & 0.79 & 237 & 14.4 & 0.39 \\
\hline 300 & 0.98 & 294 & 18.1 & 0.42 \\
\hline 300 & 1.32 & 396 & 24.8 & 0.45 \\
\hline 300 & 1.66 & 498 & 32.4 & 0.49 \\
\hline 300 & 2.00 & 600 & 38.4 & 0.50 \\
\hline
\end{tabular}

Table 3. BHT-600-I iodine propellant measured thruster performance at NASA GRC VF-7.

\begin{tabular}{|c|c|c|c|}
\hline $\begin{array}{c}\text { Discharge } \\
\text { Voltage, } \mathrm{V}\end{array}$ & $\begin{array}{c}\text { Discharge } \\
\text { Current, A }\end{array}$ & $\begin{array}{c}\text { Discharge } \\
\text { Power, } \mathrm{W}\end{array}$ & $\begin{array}{c}\text { Thrust, } \\
\mathrm{mN}\end{array}$ \\
\hline 200 & 2.18 & 436 & 30.2 \\
\hline 200 & 2.34 & 468 & 29.8 \\
\hline 250 & 0.99 & 248 & 16.5 \\
\hline 250 & 2.05 & 513 & 36.5 \\
\hline 250 & 2.18 & 545 & 35.6 \\
\hline 300 & 1.03 & 309 & 19.0 \\
\hline 300 & 2.00 & 600 & 37.2 \\
\hline 300 & 2.00 & 600 & 39.2 \\
\hline 300 & 2.21 & 663 & 40.7 \\
\hline
\end{tabular}

Table 4. BHT-600-I thrust levels at the beginning and end of Test 1 (34 hour duration) with xenon and iodine propellants.

\begin{tabular}{|l|c|c|c|c|}
\hline & \multicolumn{2}{|c|}{ 0-hr } & \multicolumn{2}{c|}{ 34-hr } \\
\hline & Xenon & Iodine & Xenon & Iodine \\
\hline Discharge Voltage, V & 300 & 300 & 300 & 300 \\
\hline Discharge Current, A & 2 & 2 & 1.98 & 2 \\
\hline Thrust, mN & 38.4 & 39.2 & 39.4 & 38 \\
\hline
\end{tabular}




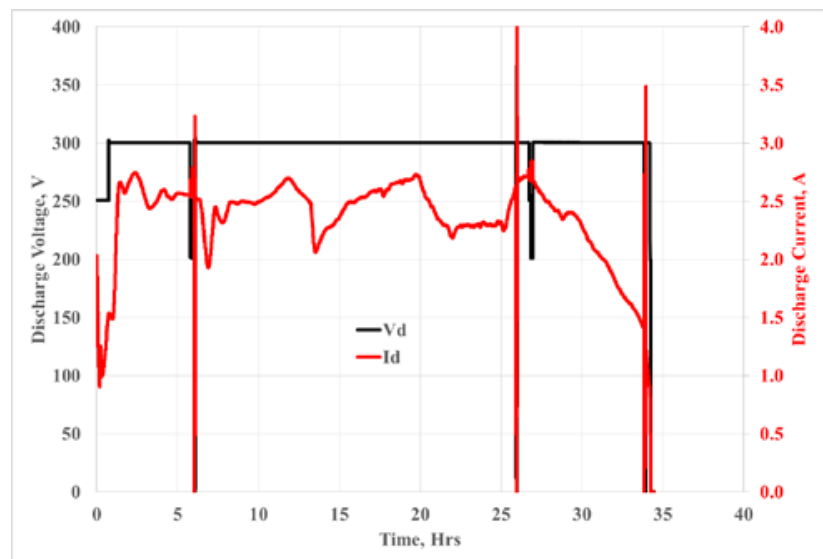

Figure 21. BHT-600-I discharge voltage and current variations during the 34 hours duration test.

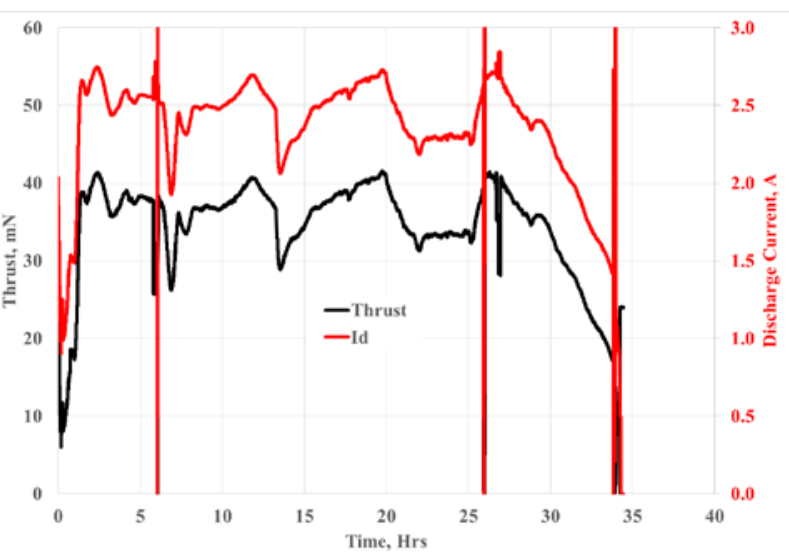

Figure 22. BHT-600-I thrust and discharge current variations during the 34 hours duration test.

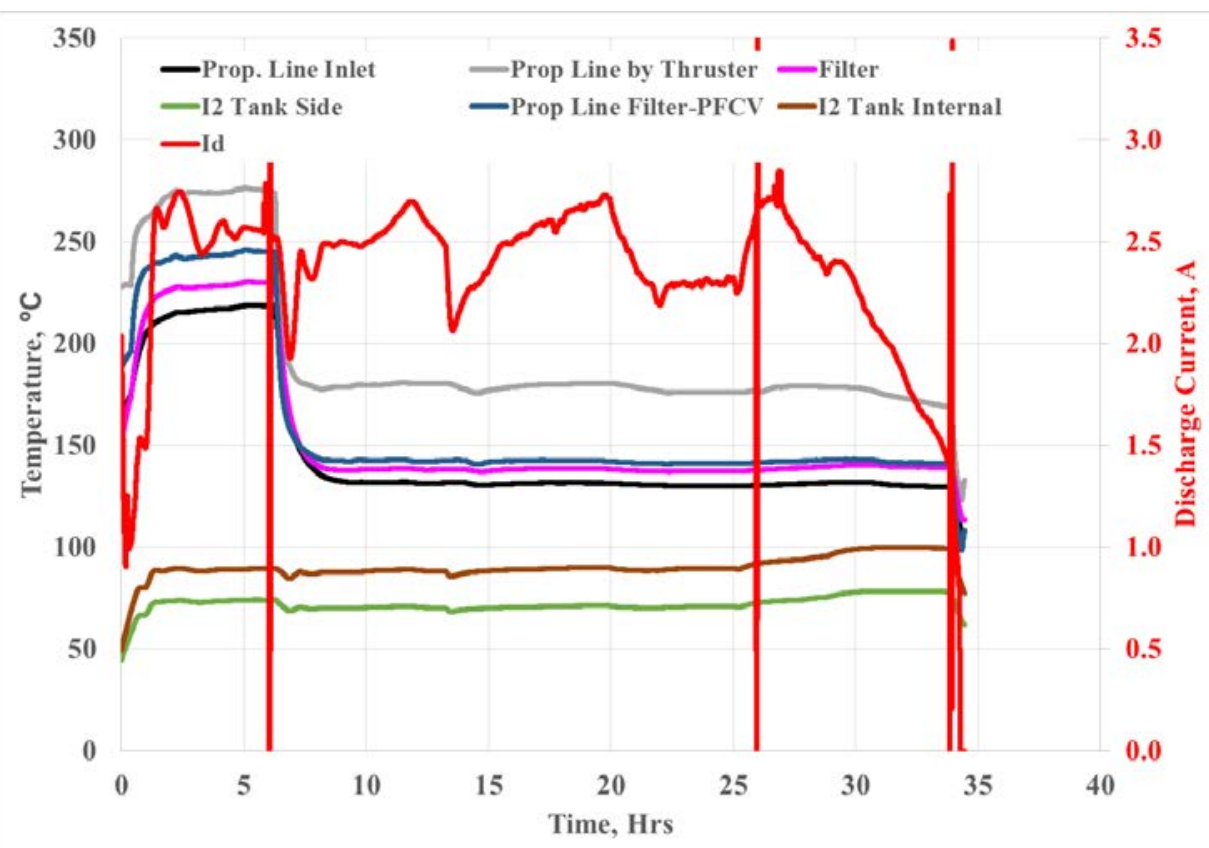

Figure 23. The iodine feed system temperature variations during the 34 hours duration test of the BHT-600-I.

Test 2 was an unattended duration test. The feed system in this test campaign was a modified version of the feed system shown in Fig. 7. The PFCV was removed to undergo failure analysis at VACCO, and the two purge valves (S2 and S3) were removed to eliminate any iodine flow paths where iodine loss could occur. In addition, a NASA GRC $\mathrm{BaO}$ impregnated porous tungsten emitter cathode was used. As with Test 1, the thruster was operated with xenon first and then iodine testing was initiated. Test 2 was run continuously, and the test lasted for approximately 46 hours in duration. During the test, the thruster was operated at a discharge voltage of $300 \mathrm{~V}$ with a discharge current target value of 2 A. Thermal throttling of the iodine tank temperature was the method used to regulate the iodine flow rate. As such, the discharge current magnitude was mostly maintained around 2 A and started to drop towards the end of the test as the iodine propellant was depleted. After exhausting the iodine propellant, performance was measured with xenon propellant, and results indicated nearly identical thruster performance when compared to the start of the test. 


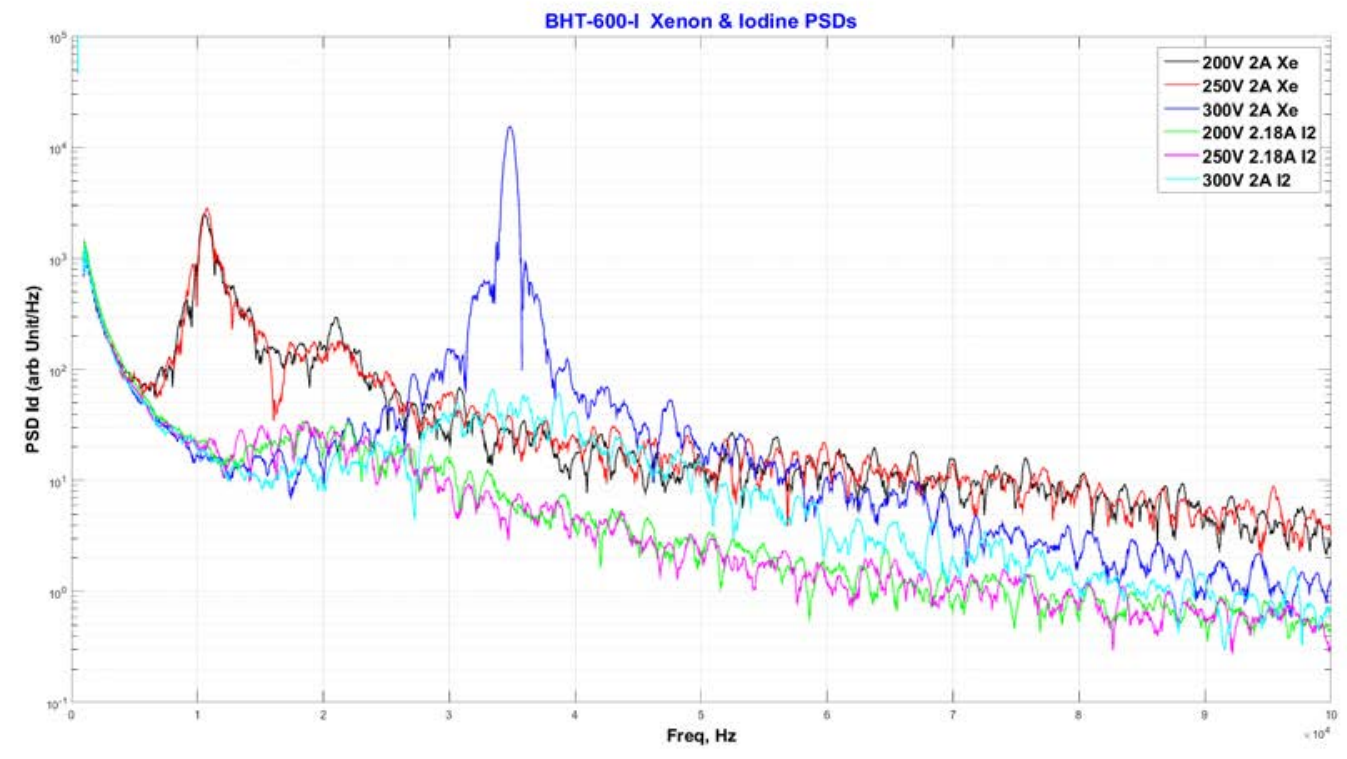

Figure 24. BHT-600-I PSD profiles for xenon and iodine operation during tests at NASA GRC VF-7.

Post Test 2 BHT-600-I thruster performance evaluation with xenon again indicated levels similar to what was measured before Test 1 . Visual inspection of the thruster indicated that the thruster magnetic circuit components and applied coatings were not affected by exposure to iodine.

\section{Summary and Future Work}

NASA continues to develop iodine Hall thrusters due to mission benefits for small spacecraft. The team of NASA GRC, NASA MSFC, and Busek Co. Inc. are working on both a flight mission and technology development activity. The Busek BHT-200-I will be qualified for flight on the iSAT mission. The BHT-600-I development activity will culminate in the delivery of an engineering model, BHT-600-I Hall thruster propulsion system. To date, extended duration tests have been conducted at NASA GRC on the EM BHT-200-I and BHT-600-I Hall thrusters. In each test the thruster performance was consistent with previous observed results and in-line with operation on xenon. Post inspection of the thrusters did not show any significant physical changes after operation with iodine. Future activities will focus on flight qualification of the BHT-200-I system, including integrated system testing with the iodine feed system, cathode, and power processing unit. Technology development will continue with the BHT-600-I to examine iodine operation at $600 \mathrm{~W}$ and to perform extended duration testing of an engineering model propulsion system after the delivery of the $600 \mathrm{~W}$ PPU. Future planned activities include:

1. Component level propellant isolator tests.

2. Component level tests of iodine-compatible cathode assemblies. Busek and NASA GRC-designed and manufactured cathode assemblies will be evaluated with iodine propellant and a reduced set of assemblies will be duration tested.

3. Integrated testing of the EM BHT-200-I with a Busek iodine-compatible cathode assembly. This test will incorporate two modified Gen 1 PFCVs, and the feed system configuration will be very similar to the iSAT spacecraft iodine feed system. This test will include cyclic tests on the BHT-200-I thruster to simulate operation on the iSAT spacecraft.

4. Upgrades to VF-7 to reduce operational costs and enhance iodine removal after testing.

5. Integrated testing of the qualification model BHT-200-I thruster with the iSAT qualification iodine feed system.

6. Integrated testing of the BHT-600-I thruster with the PPU being developed by Busek.

7. Extended duration testing of the BHT-600-I thruster to show its viability to meet projected NASA missions. 


\section{Acknowledgments}

The authors would like to thank and acknowledge NASA Space Technology Mission Directorate and NASA Glenn for supporting the iodine thruster development and testing. Lastly, the authors would like to thank Thomas Sours, Luke Sorrelle, James Schneider, and Richard Polak for supporting the testing of iodine Hall thrusters at NASA GRC.

\section{References}

1. Szabo, J., Pote, B., Paintal, S., Robin, M., Hillier, A., Branam, R.D. \& Huffman, R.E, "Performance Evaluation of an Iodine-Vapor Hall Thruster,” J. Propul. Power 28(4), 2012.

2. Szabo, J., Robin, M., Paintal, S., Pote, B., Hruby, V., and Freeman, C, "Iodine Plasma Propulsion Test Results at 1-10 kW,” IEEE T. Plasma Sci. 43(1), 141-148, 2015.

3. Tverdokhlebov, O.S., and Semenkin, A.V., "Iodine Propellant for Electric Propulsion-To Be or Not To Be," AIAA 2001-3350, July 2001.

4. Dressler, R., Chiu, Y.-H., and Levandier, D., "Propellant Alternatives for Ion and Hall Effect Thrusters,” AIAA 2000-0602, July 2000.

5. Dankanich, J.W., Szabo, J., Pote, B., Oleson, S., and Kamhawi, H, "Mission and System Advantages of Iodine Hall Thrusters," AIAA-2014-3905, July 2014.

6. McGuire, M.L., Oleson, S.R. \& Sarver-Verhey, T, "Concurrent Mission and Systems Design at NASA Glenn Research Center: The Origins of the COMPASS Team,” NASA/TM-2012-217283 and AIAA Paper 2011-7240.

7. Dankanich, J.W., Polzin, K.A., Calvert, D., and Kamhawi, H., "The Iodine Hall Thruster Demonstration Mission Concept and Development,” AIAA-2014-3910, July 2014.

8. Dankanich, J.W., Selby, M., Polzin, K., Kamhawi, H., Hickman, T., and Byrne, L., "The Iodine Satellite (iSAT) Project Development Towards Critical Design Review," 52 ${ }^{\text {nd }}$ AIAA/SAE/ASEE Joint Propulsion Conference, Salt Lake City, July 2016.

9. Polzin, K.A., et al., "Development, Demonstration, and Analysis of an Integrated Iodine Hall Thruster Feed System," presented in 52 ${ }^{\text {nd }}$ AIAA/SAE/ASEE Joint Propulsion Conference, Salt Lake City, Utah, July 2016.

10. Polzin, K.A. \& Peeples, S., "Iodine Hall Thruster Propellant Feed System for a CubeSat," AIAA 2014-3915, July 2014.

11. Monheiser, J., Hruby, V., Freeman, C., Connolly, W., and Pote, B., Development and Testing of a Low-Power Hall Thruster System"., in Micropropulsion for Small Spacecraft, M. Micci and A. Ketsdever, Eds.; AIAA Progress Series in Astronautics and Aeronautics, Reston, VA., Vol. 187, 2000, pp. 244-269.

12. Szabo, J., Pote, B., Tedrake, R., Paintal, S., Byrne, L., Hruby, V., Kamhawi, H., and Smith, T., "High Throughput 600 Watt Hall Effect Thruster for Space Exploration,” 52 ${ }^{\text {nd }}$ AIAA/SAE/ASEE Joint Propulsion Conference, Salt Lake City, Utah, July 2016.

13. Haag, T., "Thrust Stand for High-Power Electric Propulsion Devices,” Rev. Sci. Instrum. 62(5), 1186-1191, 1991.

14. Leray, P., et al., "Spatially Resolved Emission Spectroscopy Along a SPT Channel, Interpretation of Data by a Collisional-Radiative Model,” International Electric Propulsion Conference Paper IEPC-97-054, Cleveland, Ohio 1997.

15. Karabadzhak, G. F., and Semenkin, A. V., "Investigation of TAL Optical Emissions,” International Electric Propulsion Conference Paper IEPC-97-131, Cleveland, Ohio, 1997.

16. Pagnon, D., Touzeau, M., and Lasgorceix, P., "Control of the Ceramic Erosion by Optical Emission Spectroscopy: Parametric Studies of SPT 100-ML,” AIAA Paper 2004-3773, July 2004.

17. Hargus, W. A., "Optical Boron Nitride Insulator erosion Characterization of a 200 W Xenon Hall Thruster," 41st AIAA Joint Propulsion Conference, AIAA paper 2005-3529, Tucson, Arizona, 2005.

18. Cho, S., et al., "Experimental and Numerical Study on a Hall Thruster Insulator Erosion,” International Electric Propulsion Conference Paper IEPC-2011-078, Wiesbaden, Germany, September 2011.

19. Shmelev, A. V., and Lovtsov, A., S., "Investigation of Discharge Power Influence on Erosion Rate of SPT Discharge Chamber Using Spectroscopic Method,” International Electric Propulsion Conference Paper IEPC2011-024, Wiesbaden, Germany, September 2011

20. Kozintseva, M. V., et al., "Forecast of Erosion Rate of SPT K-0 Channel Insulators by Spectral Measurements," International Electric Propulsion Conference Paper IEPC-2011-293, Wiesbaden, Germany, September 2011.

21. Cho, S., et al., "Hall Thruster Channel Wall Erosion Rate Measurement Method Using Multilayer Coating Chip," 46 ${ }^{\text {th }}$ AIAA Joint Propulsion Conference, AIAA-2010-6697, Nashville, Tennessee, July 2010.

22. Arabadzhak, G. F. and Semenkin, A. V., "Evaluation of a Xenon Operating Hall Thruster Body Erosion Rate Through Analysis of Its Optical Spectra," 37th AIAA Joint Propulsion Conference, AIAA-2001-3889, Salt Lake City, Utah, July 2001. 
23. Chiu, Y. H., et al., "Passive Optical Diagnostic of Xe Propelled Hall Thrusters, Part 1: Emission Cross Sections, Journal of Applied Physics 99113304 (2006).

24. Williams, G. J., Soulas, G. C., and Kamhawi, H., “Optical Diagnostic Characterization of High-Power Hall Thruster Wear and Operation,” 48th AIAA/ASME/SAE/ASEE Joint Propulsion Conference, AIAA Paper 20124036, Atlanta, GA, July, 2012.

25. Williams, G. J., and Kamhawi, H., “Optical Emission Characterization of High-Power Hall Thruster Wear,” JANNAF Propulsion Meeting, April, 2013.

26. Chiu, Y-H, and Prince, B. D., “Optical Emission Spectra of the Iodine Hall Effect Thruster," 48 ${ }^{\text {th }}$ AIAA Joint Propulsion Conference, AIAA Paper 2012-3872, August 2012. 